\title{
Interação tectônica entre bacias sucessoras no domínio externo do Orógeno Araçuaí: estudo de caso da região de Planalto de Minas, Minas Gerais
} The tectonic interaction between subsequent basins in the external domain of the Araçuai Orogen: a case study of Planalto de Minas Region, Minas Gerais

\author{
Maria Eugênia Silva de Souza', Maximiliano de Souza Martins ${ }^{1}$, Mariana de Resende Madeira ${ }^{1}$, \\ Gláucia Nascimento Queiroga ${ }^{1}$, Maria Silvia Carvalho Barbosa ${ }^{1}$ \\ 'Departamento de Geologia, Escola de Minas, Universidade Federal de Ouro Preto - UFOP - Campus Morro do Cruzeiro, s/n, \\ Bauxita, CEP 35400-000, Ouro Preto, MG, BR (messouza.op@gmail.com; messouza.op@gmail.com; maximilianomartins@ \\ yahoo.com.br; marirmadeira@gmail.com; glauciaqueiroga@yahoo.com.br; mscbarbosa@gmail.com)
}

Recebido em 22 de março de 2016; aceito em 22 de março de 2017

\begin{abstract}
Resumo
O Supergrupo Espinhaço Meridional e o Grupo Macaúbas, em Minas Gerais, são as maiores expressões geotectônicas dos ciclos de fragmentação sucessivos que atingiram o paleocontinente São Francisco-Congo desde o Estateriano até o Criogeniano. O mapeamento geológico em escala 1:25.000 da região de Planalto de Minas, localizada no centro-norte do estado, revelou a ocorrência da Formação São João da Chapada ( $c a .1 .7 \mathrm{Ga}$, Supergrupo Espinhaço) diretamente sobreposta por uma sequência metavulcano-sedimentar toniana do Grupo Macaúbas (ca. 889 Ma), aqui designada de Formação Planalto de Minas. A integração geológica-geofísica revelou ainda que esta área permaneceu como um alto estrutural do final do Estateriano até o Toniano. A existência do alto estrutural de Planalto de Minas é o reflexo do complexo arranjo estrutural de rifteamentos sobrepostos, com formação e interação de um meio-gráben, ou sistema ramificado de meio-grabens, que exerceram importante controle tectono-estratigráfico na arquitetura — formação e evolução — da bacia Macaúbas.
\end{abstract}

Palavras-chave: Bacias do Tipo Rifte; Alto Estrutural de Planalto de Minas; Meio-gráben; Geofísica; Supergrupo Espinhaço; Grupo Macaúbas.

\begin{abstract}
In Minas Gerais state, the Southern Espinhaço Supergroup and Macaúbas Group are the major geotectonic expression of the crustal sucessives fragmentation cycles that shaped the São Francisco-Congo paleocontinent between the Statherian and Cryogenian periods. The geological mapping (1:25.000) in Planalto de Minas region (central-northern portion of Minas Gerais) revealed the occurrence of the São João da Chapada Formation (ca. 1.7 Ga, Espinhaço Supergroup) directly superimposed by a Tonian metavolcano-sedimentary sequence, here called Planalto de Minas Formation (Macaúbas Group), dated at $c a .889 \mathrm{Ma}$. The geological-geophysical data integration revealed that the Planalto de Minas region remained as a structural high, and this is a reflection of the complex structural arrangement of superimposed rifts, with the formation and interaction among one half-graben or branched system of half-grabens, being important for the tectonic-stratigraphy control — on architecture and evolution — of the Macaúbas basin.
\end{abstract}

Keywords: Rift Basins; Structural High of Planalto de Minas; Half-graben; Geophysics; Espinhaço Supergroup; Macaúbas Group. 


\section{INTRODUÇÃO}

O paleocontinente São Francisco-Congo, consolidado ao final do Orosiriano, registra em seu interior e em suas margens uma série de eventos extensionais, amplamente distribuídos no tempo e no espaço, representados por bacias sedimentares pré-cambrianas das quais serviu ao mesmo tempo de substrato e de área fonte. Na margem leste desse bloco crustal, o Supergrupo Espinhaço Meridional e grande parte do Grupo Macaúbas, em Minas Gerais, são as maiores expressões geotectônicas dos ciclos de fragmentação que o atingiram, desde o Estateriano até o Criogeniano, culminando com a formação de crosta oceânica em torno de $640 \mathrm{Ma}$ (Alkmim e Martins-Neto, 2001; Pedrosa-Soares e Alkmim, 2011). O fechamento dessas bacias se deu ao final do Neoproterozoico, edificando o Orógeno Araçuaí-Congo Ocidental (Pedrosa-Soares et al., 2001).

O Supergrupo Espinhaço Meridional é entendido como um rifte intracontinental de idade estateriana $(c a .1,7 \mathrm{Ga})$, sucedido por uma bacia intracratônica, cujo processo inicial de subsidência ocorreu por implantação de um rifte, no período Esteniano ( $c a .1,18 \mathrm{Ga}$ ). A ausência de um ciclo bacinal intermediário $(1,6 \mathrm{Ga}-1,3 \mathrm{Ga})$, presente apenas na Chapada Diamantina, a norte dessa região, permite inferir que a atual área ocupada pela Serra do Espinhaço Meridional comportou-se como um alto estrutural ou área de não deposição entre o Estateriano e o início do Esteniano (Chemale et al., 2012).

A região do distrito de Planalto de Minas (Figura 1) expõe um segmento notável da interação tectônica entre duas bacias pré-cambrianas distintas e sobrepostas, estando preservados o modo de ocorrência e as relações de contato entre o ramo mais setentrional do sistema de riftes Estateriano do Supergrupo Espinhaço em Minas Gerais, que posteriormente funcionou como um alto estrutural do embasamento para uma sequência vulcano-sedimentar toniana, atribuída ao Grupo Macaúbas, revelando-se um importante laboratório natural para estudos tectônicos em bacias do tipo rifte.

\section{MÉTODOS E MATERIAIS}

A região de Planalto de Minas localiza-se entre as serras do Espinhaço Meridional e Setentrional, em Minas Gerais. Numa primeira etapa, procedeu-se a revisão bibliográfica acerca dos trabalhos mais recentes (e referências neles contidos) que dizem respeito à região de Planalto de Minas e aos terrenos adjacentes que se relacionam com a geologia dessa área (Chula et al., 1995; Fogaça, 1996; Noce, 1997; Grossi-Sad et al., 1997; Gradim et al., 2005; Martins et al., 2008). De igual maneira, procurou-se estabelecer o estado da arte sobre a evolução tectono-estratigráfica das bacias Espinhaço (Martins-Neto e Alkmim, 2000; Chemale et al., 2012) e Macaúbas (Pedrosa-Soares e Alkmim, 2011; Babinski et al., 2005, 2012; Castro et al., 2013; Kuchenbecker et al., 2015) em Minas Gerais, bem como o posicionamento geotectônico da região no contexto do Orógeno Araçuaí (Pedrosa-Soares et al., 2001, 2007; Alkmim et al., 2006; Pedrosa-Soares e Alkmim, 2011).

A cartografia geológica em escala 1:25.000 foi apoiada por mapas geofísicos que muito auxiliaram na determinação das relações de contato e na delimitação de parte das próprias unidades geológicas mapeadas, sobretudo nas áreas que possuem problemas, isolados ou em comunhão, com relação à quantidade e qualidade dos afloramentos, devido principalmente à alteração hidrotermal e/ou intempérica. $\mathrm{O}$ apoio dos mapas geofísicos estendeu-se também para a determinação dos padrões estruturais dessa região.

Para a confecção dos mapas geofísicos foi utilizado o banco de dados da Área 11A (Jaíba - Montes Claros Bocaiúva), pertencente ao programa 2008/2009 de levantamento aerogeofísico do estado de Minas Gerais, executado pela Companhia de Desenvolvimento Econômico de Minas

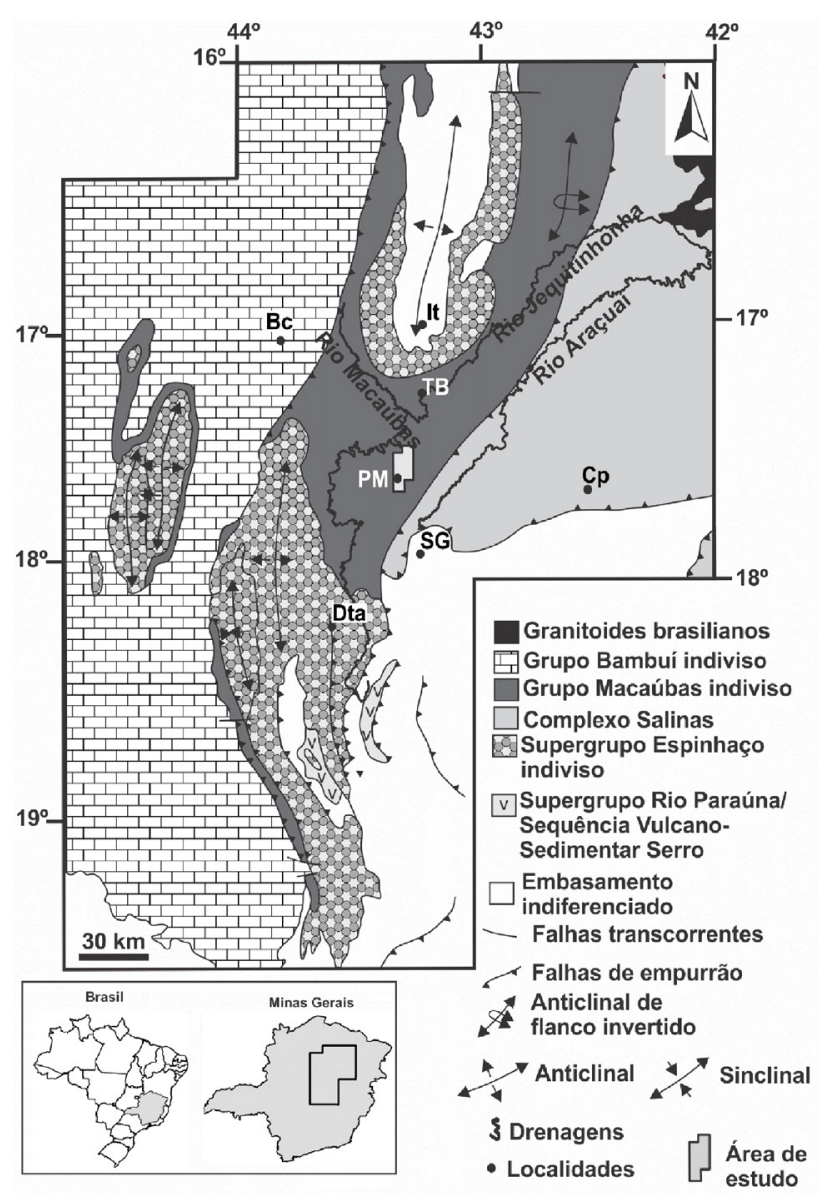

Bc: Bocaiúva; Cp: Capelinha; Dta: Diamantina; It: Itacambira; PM: Planalto de Minas; SG: São Gonçalo do Rio Preto; TB: Terra Branca. Modificado de Uhlein (1991).

Figura 1. Mapa geológico regional da Serra do Espinhaço, em Minas Gerais, com a localização da área de estudo. 
Gerais (CODEMIG) em parceria com o Serviço Geológico Brasileiro (CPRM) (Lasa Engenharia e Prospecções, 2007). Os parâmetros estão sistematizados na Tabela 1 .

O banco de dados foi tratado por meio do software Oásis Montaj 7.01, gerando mapas temáticos e mapas de anomalias pelo método de mínima curvatura, com tamanho de células predefinidas.

Diversos mapas magnetométricos e radiométricos foram elaborados, sendo os com as melhores respostas, conforme os objetivos do estudo, a amplitude de sinal analítico (ASA) e o Up500 da magnetometria; e o canal de potássio $\left(\mathrm{K}_{\mathrm{t}}\right)$ da radiometria.

Além dos mapas temáticos, uma deconvolução de Euler foi realizada a fim de estimar a profundidade média das fontes magnéticas e uma possível visualização do arcabouço estrutural da área-alvo. Para tal, utilizaram-se tamanhos de janelas pequenos a fim de obter maior resolução de resultados. Para o perfil AA', o tamanho escolhido foi 11, e para o perfil NW-SE, 7. Considerando ambos, o índice estrutural escolhido foi 1 (que retoma a um modelo geológico do tipo contato, conforme Reid et al.,1990), e profundidade máxima de estimativa de $2.000 \mathrm{~m}$.

A integração entre os dados geológicos e geofísicos da região de Planalto de Minas, contextualizados regionalmente, constituiu a base para as interpretações acerca da caracterização e evolução dos processos de rifteamento no Estateriano e no Toniano nessa região. As interpretações postuladas, baseadas no reconhecimento e na distribuição de meio-gráben (ou sistemas de meio-grabens), fundamentaram-se nos trabalhos de Kuchle (2010) e Kearey et al. (2014).

\section{CONTEXTUALIZAÇÃO REGIONAL}

O paleocontinente São Francisco-Congo remonta a uma longa história de evolução crustal, consolidando-se como um núcleo

Tabela 1. Parâmetros do aerolevantamento geofísico realizado pelo Conselho de Desenvolvimento Econômico do Estado de Minas Gerais (CODEMIG) e Serviço Geológico Brasileiro (CPRM) (Lasa Engenharia e Prospecções, 2007) e utilizados neste trabalho.

\begin{tabular}{|c|c|}
\hline Parâmetros & Valores \\
\hline Altura de voo & $100 \mathrm{~m}$ \\
\hline Espaçamento médio entre as linhas de voo & $500 \mathrm{~m}$ \\
\hline $\begin{array}{l}\text { Espaçamento médio entre as linhas de } \\
\text { controle }\end{array}$ & $10.000 \mathrm{~m}$ \\
\hline Direção das linhas de voo & $\mathrm{N} 25^{\circ} \mathrm{W}$ \\
\hline Direção das linhas de controle & $\mathrm{N} 65^{\circ} \mathrm{E}$ \\
\hline $\begin{array}{l}\text { Intervalo médio de amostragem } \\
\text { (magnetometria) }\end{array}$ & $7,6 \mathrm{~m}$ \\
\hline $\begin{array}{l}\text { Intervalo médio de amostragem } \\
\text { (radiometria) }\end{array}$ & $76 \mathrm{~m}$ \\
\hline Período de levantamento & $\begin{array}{l}\text { Maio - setembro } \\
\text { de } 2009\end{array}$ \\
\hline
\end{tabular}

crustal estável ao final do período Orosiriano (ca. 1,9 Ga). A partir daí, passa a ser afetado por uma série de eventos tafrogenéticos sucessivos, desde o Estateriano $(1,8 \mathrm{Ga})$ até o Criogeniano (650 Ma), culminando com a formação de bacias oceânicas que delimitaram o contorno do futuro cráton homônimo por meio da inversão e acreção das bacias marginais ao antepaís, no final do Neoproterozoico, estendendo-se até o início do Cambriano. O cráton São Francisco-Congo manteve-se íntegro até a abertura do Atlântico Sul, quando foi fragmentado e separado em duas peças complementares que atualmente compõem parte da Plataforma Sul-americana e do continente africano (Alkmim e Martins-Neto, 2001).

O orógeno neoproterozoico Araçuaí (Pedrosa-Soares et al., 2001) abrange toda a faixa de dobramentos de mesmo nome, originalmente definida por Almeida (1977), estendendo-se desde o limite leste do cráton São Francisco até o litoral atlântico, aproximadamente entre os paralelos $15 \mathrm{e}$ $21^{\circ} \mathrm{S}$. Em seu domínio externo (ou ocidental), Alkmim et al. (2006) individualizaram o cinturão de cavalgamentos Serra do Espinhaço Meridional como uma zona caracterizada pela ocorrência marcante de dobramentos e falhamentos associados a rochas de baixo grau metamórfico, possuindo direção meridiana e vergência em direção ao cráton São Francisco. Nessa região estão materializadas as melhores relações estratigráficas e estruturais entre os dois principais sistemas de riftes sucessores que antecederam a fragmentação final do paleocontinente São Francisco-Congo em sua porção oriental.

O Supergrupo Espinhaço (Schobbenhaus, 1993; Schöll e Fogaça, 1979) compõe e sustenta a serra homônima, a qual se estende por aproximadamente $1.200 \mathrm{~km}$ segundo o meridiano, distribuindo-se ao longo do Orógeno Araçuaí ou como cobertura sobre o cráton São Francisco. É formado por associações vulcano-sedimentares na base, sobreposto por um espesso pacote de sedimentos siliciclásticos em direção ao topo, com porções localizadas de sedimentos carbonáticos. É interpretado como uma bacia ensiálica do tipo rifte-sinéclise, inicialmente nucleada no Estateriano, com desenvolvimento bacinal policíclico e descontínuo (Alkmim, 2004).

Pflug (1968) definiu oito formações consideradas fundamentais para o Supergrupo Espinhaço em sua parcela Meridional. Estratigrafia está mantida por todos os trabalhos que se seguiram desde então, respaldando as diferentes propostas de agrupamento de parte dessas unidades segundo os distintos estágios de evolução (e.g. Dussin e Dussin, 1995; Almeida-Abreu, 1995; Martins-Neto e Alkmim, 2000).

No atual estado da arte, considera-se que o Supergrupo Espinhaço Meridional é formado por duas grandes sucessões sedimentares separadas por discordância angular, interpretada como dois ciclos de preenchimento de bacia (Chemale et al., 2012):

- o primeiro Estateriano (1,78 - 1,70 Ga), interpretado como rifte intracontinental, representado pelas formações Bandeirinha e São João da Chapada, esta contendo 
corpos de filitos hematíticos, produtos de deformação, metassomatismo e intemperismo de basaltos alcalinos datados em torno de 1,7 Ga (e.g. Knauer e Schrank, 1994; Dussin e Dussin, 1995; Cabral et al., 2012);

- outro Esteniano-Toniano (1,18 - 0,91 Ga) como uma bacia intracratônica cujo processo inicial de subsidência ocorreu por implantação de um rifte, atribuído à Formação Sopa-Brumadinho, detentora dos depósitos conglomeráticos portadores de diamantes, localmente com tufos intercalados. A fase flexural da bacia é marcada pelos sedimentos eólicos e marinhos da Formação Galho do Miguel e do Grupo Conselheiro Mata, respectivamente.

O Grupo Macaúbas representa a principal unidade sedimentar da bacia precursora do orógeno homônimo (PedrosaSoares et al., 2001; Babinski et al., 2012) e registra um evento tafrogênico regional no Toniano (Pedrosa-Soares et al., 2001; Pedrosa-Soares e Alkmim, 2011). Apresenta polaridade sedimentar e desenvolvimento faciológico segmentado no sentido NNW-SSE, com registro localizado dos estágios de desenvolvimento bacinal de um rifte continental para uma margem passiva (Noce, 1997; Kuchenbecker et al., 2015). De maneira geral, comporta uma sequência proximal, formada por depósitos pré-glaciais, glaciais e transicionais, e outra distal, encerrando restos ofiolíticos de uma proto-crosta oceânica de $640 \mathrm{Ma}$ (Pedrosa-Soares e Alkmim, 2011; Queiroga et al., 2007).

O estágio rifte da bacia Macaúbas é relativamente bem documentado ao longo do meridiano $43^{\circ} 30^{\prime} \mathrm{W}$, zona de ocorrência das sequências metavulcano-sedimentares (xistos verdes metabasálticos e quartzitos impuros) de idade entre 1,0 Ga e $900 \mathrm{Ma}$ (Machado et al., 1989; Babinski et al., 2005). Contudo, Castro et al. (2013) evidenciam a ramificação do sistema de rifteamento toniano para leste desse setor, caracterizando a formação de um alto estrutural em algum momento posterior a $957 \mathrm{Ma}$.

Na região de Desembargador Otoni - Planalto de Minas, distritos do município de Diamantina, Schrank et al. (1978), Chula et al. (1995) e Grossi-Sad et al. (1997) atribuíram o pacote de xistos verdes como parte do magmatismo bimodal do Supergrupo Espinhaço, cujo equivalente ácido seriam os corpos de metarriolitos presentes na região, datados por Machado et al. (1989) em ca. 1,7 Ga. Todo esse pacote magmático e rochas metassedimentares intercaladas foram interpretados por esses autores como pertencentes ao Supergrupo Espinhaço, assertiva que contraria a proposta estratigráfica de Hettich (1973), para quem o conjunto rochoso estaria posicionado no Grupo Macaúbas, estendendo-se para norte, na região de Terra Branca. Contudo, Gradim et al. (2005), Babinski et al. (2005) e Martins et al. $(2008$, 2011) retomam a estratigrafia de Hettich (1973) e de Karfunkel e Karfunkel (1977) para as folhas Carbonita e Itacambira, respectivamente. Texturas e estruturas primárias encontram-se preservadas nos xistos verdes do Alto Rio Araçuaí, formalizados como Membro Rio Preto (Formação Chapada Acauã) por Gradim et al. (2005) e caracterizados como a interação entre vulcanismo basáltico submarino, sedimentação vulcanoclástica e vulcanismo relacionado a fontes de alta produtividade nos estágios iniciais de abertura da bacia Macaúbas.

\section{GEOLOGIA DA REGIÃO DE PLANALTO DE MINAS - MINAS GERAIS}

O mapeamento geológico da região abrangida pelo distrito de Planalto de Minas apresenta, da base para o topo, a Formação São João da Chapada (Supergrupo Espinhaço Meridional) sobreposta pelo Grupo Macaúbas, representado por uma espessa pilha metavulcano-sedimentar sem designação formal (Figura 2).

A Formação São João da Chapada possui destacada expressão morfológica, constituindo o domínio serrano de direção meridiana que marca o relevo desta área. A unidade ocorre na forma de quartzitos com elevada maturidade composicional, mas baixa maturidade textural. Possui granulação variável de média a grossa, com estratificações cruzadas acanaladas de porte variável $(0,50-1,5 \mathrm{~m})$ e plano-paralelas. Em contatos abruptos com os quartzitos, ocorrem corpos heterogêneos e parcialmente intemperizados de filitos hematíticos (Figura 3A), compostos por sericita (70\%), óxidos de ferro $(27 \%)$ e quartzo (3\%), com microestrutura inequigranular (muito fina a média) lepidoblástica (Figura 3B).

A associação entre filitos hematíticos e quartzitos intercalados constitui a evidência inequívoca da Formação São João da Chapada, na região de Planalto de Minas. Esse pacote rochoso foi anteriormente designado por Chula et al. (1995) como Formação Serra do Atalho (Supergrupo Espinhaço), contendo, ainda, corpos isolados de metarriolitos. Segundo Grossi-Sad et al. (1997), os filitos hematíticos presentes na Folha Carbonita podem ser facilmente confundidos com metarriolitos em função da forte alteração hidrotermal a que foram submetidos. De acordo com esses autores, os filitos hematíticos encontram-se destituídos de suas características macro e microscópicas peculiares, apresentando também composição química única (baixo teor de $\mathrm{SiO}_{2}$, elevado teor de $\mathrm{K}_{2} \mathrm{O}$ e norma CIPW sui generis). Por essas características, os sericita xistos classificados como metarriolitos por Schrank et al. (1978) e Chula et al. (1995) foram, em parte, considerados filitos hematíticos hidrotermalizados por Grossi-Sad et al. (1997).

O Grupo Macaúbas é formado por uma expressiva unidade metavulcano-sedimentar, aqui designada Formação Planalto de Minas, que sobrepõe diretamente, por contato brusco, a Formação São João da Chapada em sua parte leste, sendo sobreposta pela mesma unidade na porção centro-oeste por meio de falha de empurrão (Figura 2).

No seu conjunto, a Formação Planalto de Minas é caracterizada por intercalações decamétricas a milimétricas entre quartzitos e corpos de xistos verdes strictu sensu, cujas intercalações 
definem uma única pilha metavulcano-sedimentar, não havendo mais de um nível desse. Os quartzitos são compostos essencialmente por quartzo, sericita e magnetita. São muito friáveis, texturalmente finos, bem selecionados e têm estruturas primárias preservadas, como estratificação cruzada acanalada de pequeno porte ( $30 \mathrm{~cm}$ em média) e plano-paralela (Figura 4).

Os xistos verdes apresentam feições ígneas primárias, como brechas, pillow lava e amígdalas. Essas rochas são essencialmente compostas por actinolita, plagioclásio, epidoto, clorita e quartzo, podendo conter titanita e calcita. Texturalmente variam de muito finas a finas, apresentando microestrutura nematoblástica e, pontualmente, granonematoblástica. A paragênese principal define a fácies metamórfica xisto verde, o que permitiu a preservação das estruturas primárias que, associadas a outras características, contribuíram para a distinção de três litofácies:

- xistos verdes destituídos de feições primárias (Figura 5A);

- xistos verdes com brechas e clastos fluidais (Figura 5B); e

- xistos verdes almofadados (Figura 5C).
Em comum, todas as litofácies apresentam um bandamento composicional marcado por alternância de cores verde-escuro e verde-claro, com espessuras variando de milimétricas a centimétricas (Figura 5D). Esse é um bandamento de origem metamórfica, no qual as porções escuras são dominadas por actinolita, epidoto e clorita, e as claras por plagioclásio e quartzo. Todas as litofácies apresentam amígdalas, em maior ou menor volume, preenchidas por epidoto e quartzo, sendo que pontualmente também são observáveis em escala microscópica (Figura 6).

Do ponto de vista estrutural, a região de Planalto de Minas é marcada por uma falha de empurrão contínua, de direção meridiana e com vergência para oeste, sobrepondo o Supergrupo Espinhaço (Formação São João da Chapada) sobre a sequência metavulcano-sedimentar do Grupo Macaúbas na porção centro-oeste da área (Figura 7A). A partir dessa estrutura, em direção a leste, o Supergrupo Espinhaço constitui o embasamento do Grupo Macaúbas.
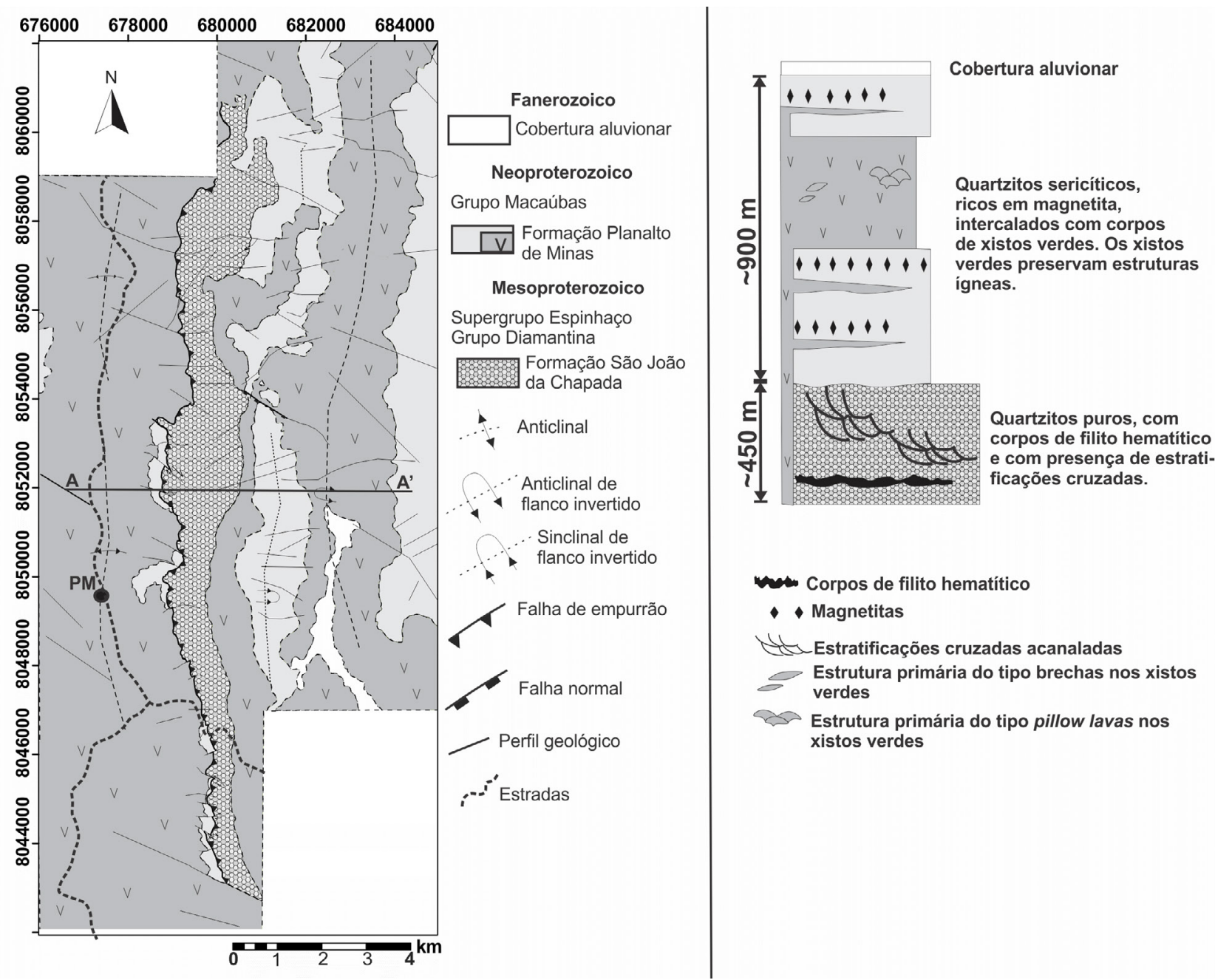

Corpos de filito hematítico

$\checkmark$ Magnetitas

V_Lstratificações cruzadas acanaladas

$\longrightarrow$ Estrutura primária do tipo brechas nos xistos verdes

Estrutura primária do tipo pillow lavas nos xistos verdes

PM: Planalto de Minas.

Figura 2. Mapa geológico e coluna estratigráfica da região de Planalto de Minas, Minas Gerais. 
A natureza dos contatos não pode ser determinada em função de que todos os litotipos que caracterizam a Formação São João da Chapada, e especialmente a sequência metavulcano-sedimentar, encontram-se cisalhados.

$\mathrm{O}$ trend estrutural acompanha a orientação da falha de empurrão, tendo correspondência no padrão morfológico da área e nas estruturas tectônicas presentes em escala de afloramento. A distribuição do acamamento sedimentar é orientada segundo a direção NS, com caimentos suaves para leste (plano médio de 90/22 em dip/direction), ocorrendo o mesmo com a foliação $S_{1}$, definida pela orientação dos minerais micáceos nos quartzitos e xistos verdes, assim como dos prismas de actinolita também nos xistos verdes (Figura 7B). A atitude média da foliação $S_{1}$ assemelha-se ao acamamento $(94 / 30)$, no entanto, sua inclinação pode ser subvertical em alguns pontos (Figura 7C). No domínio do bloco cavalgante, a leste da falha de empurrão, foram inferidos sinclinais e anticlinais fechados a invertidos para a sequência metavulcano-sedimentar do Grupo Macaúbas, com plano-axial segundo o meridiano e eixos sub-horizontais, com caimento predominante para NNE, como já inferido por Grossi-Sad et al. (1997).

Uma segunda foliação $S_{2}$ ocorre perturbando a primeira, sendo penetrativa a espaçada e observável somente nos xistos verdes. Sua orientação preferencial é N-S e seu caimento é moderado para oeste (plano médio de 292/44) (Figura 7D). Subordinada à segunda foliação ocorre uma lineação de crenulação que cai preferencialmente para NNE, com caimentos subordinados para SSW. Essa segunda foliação assemelha-se, no contexto regional, às estruturas descritas por Alkmim et al. (2006) como pertencentes à Zona de Cisalhamento Chapada Acauã, registrando o colapso gravitacional do Orógeno Araçuaí.

\section{INTEGRAÇÃO GEOLÓGICA-GEOFÍSICA DA REGIÃO DE PLANALTO DE MINAS}

Diversos mapas geofísicos temáticos magnetométricos e radiométricos foram produzidos (Madeira, 2014; Souza, 2016). Entre os principais, os mapas radiométricos de $\mathrm{K}_{\mathrm{t}}$ corroboram a existência da Formação São João da Chapada na região, uma vez que esta unidade coincide com uma forte anomalia de potássio (K) (Figura 8), à qual associa-se o alto conteúdo de deste elemento químico dos filitos hematíticos.

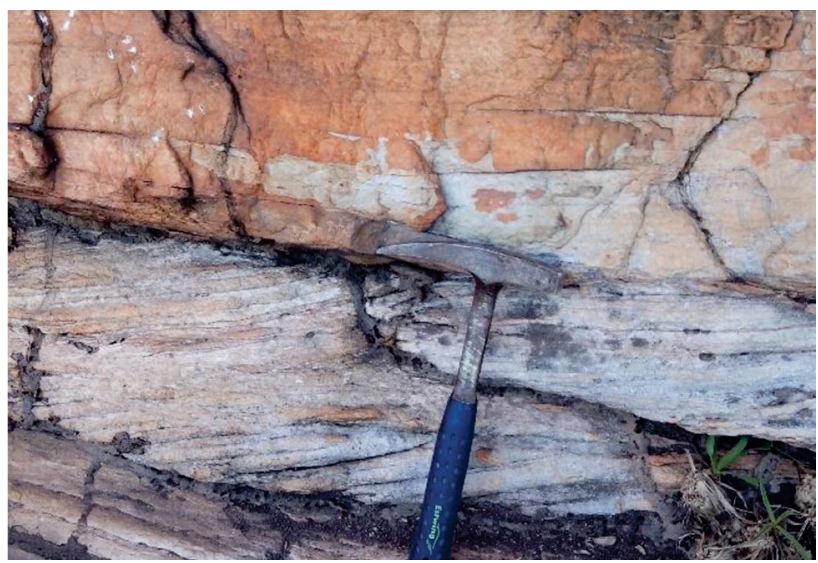

Figura 4. Estratificação acanalada de pequeno porte no magnetita-sericita quartzito da pilha metavulcano-sedimentar.
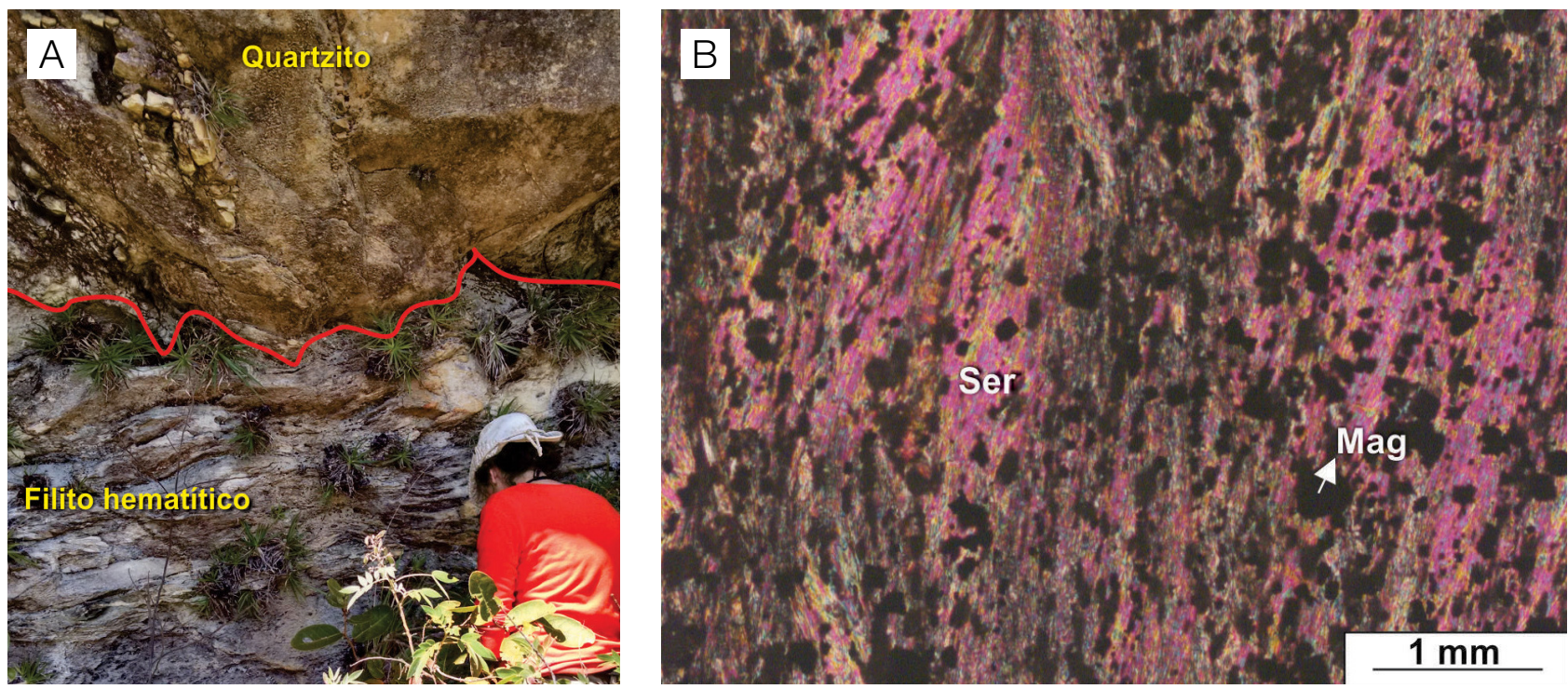

Ser: sericita; Mag: magnetita.

Figura 3. (A) Formação São João da Chapada, com contato abrupto (indicado pela linha vermelha) entre seus litotipos principais; (B) fotomicrografia do filito hematítico, com polarizadores cruzados, evidenciando a sua composição essencialmente sericítica e com óxidos de ferro. 
O mapa magnetométrico de ASA (Figura 9) apresentou sólidas respostas no sentido de corroborar a existência da falha de empurrão, responsável pela inversão estratigráfica na região, além de ter evidenciado a presença de diversos lineamentos geofísicos secundários de direção $\mathrm{EW}$, que possuem expressão localizada na geomorfologia da área.

Uma deconvolução de Euler, realizada coincidentemente com a seção geológica no intuito de visualizar em profundidade o arcabouço estrutural, também corroborou a existência da falha de empurrão, bem como a presença de dobras fechadas de flancos invertidos (Figura 10A).

Expressivo lineamento geofísico de orientação NE-SW e não aflorante é bem delineado no mapa magnetométrico de ASA (Figura 9). Uma segunda deconvolução de Euler foi realizada perpendicularmente a esse lineamento no intuito de visualizar qual é o tipo de estrutura associada a ele, e evidenciou que essa estrutura não aflorante (indicada pela seta preta na Figura 10B) pode estar relacionada a corpos máficos que não alcançaram grandes profundidades (chegando até os $700 \mathrm{~m}$ ). A localização do lineamento em questão é concordante com a região de ocorrência de xistos verdes cujas feições primárias preservadas indicam proximidade com os edifícios vulcânicos. De tal forma, esse lineamento pode apontar a localização de parte dos condutos vulcânicos.

As deconvoluções de Euler (Figura 10) mostraram também a resposta de outra estrutura não aflorante e mais profunda (1250 - $1800 \mathrm{~m}$; indicada pelas setas cinzas). O mapa magnetométrico de continuação para cima Up500 (Figura 11) caracteriza um conjunto de rochas cristalinas, devendo se tratar, portanto, do embasamento cristalino regional.

\section{BACIAS SUCESSORAS NO DOMÍNIO EXTERNO DO ORÓGENO ARAÇUAÍ: ARQUITETURA RESULTANTE DE INTERAÇÕES POLIFÁSICAS}

Riftes, ou sistema de riftes, constituem a resposta na crosta rasa aos esforços desviatórios impostos a uma porção
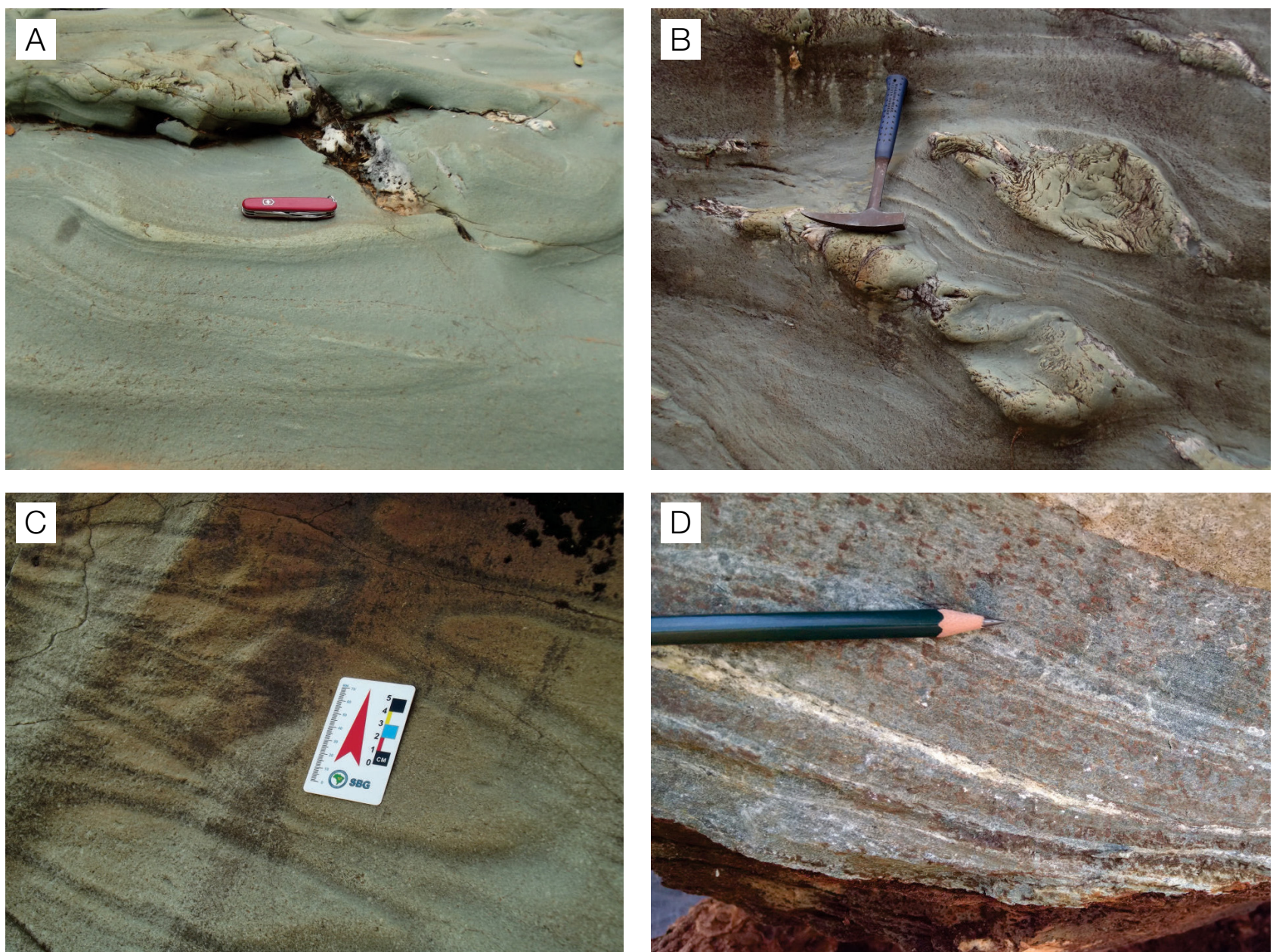

Figura 5. Características macroscópicas dos corpos de xisto verde. (A) xistos verdes destituídos de feições primárias; (B) xistos verdes com brechas; (C) xistos verdes almofadados; (D) bandamento composicional de origem metamórfica, marcado por alternâncias de cores claras e escuras. 

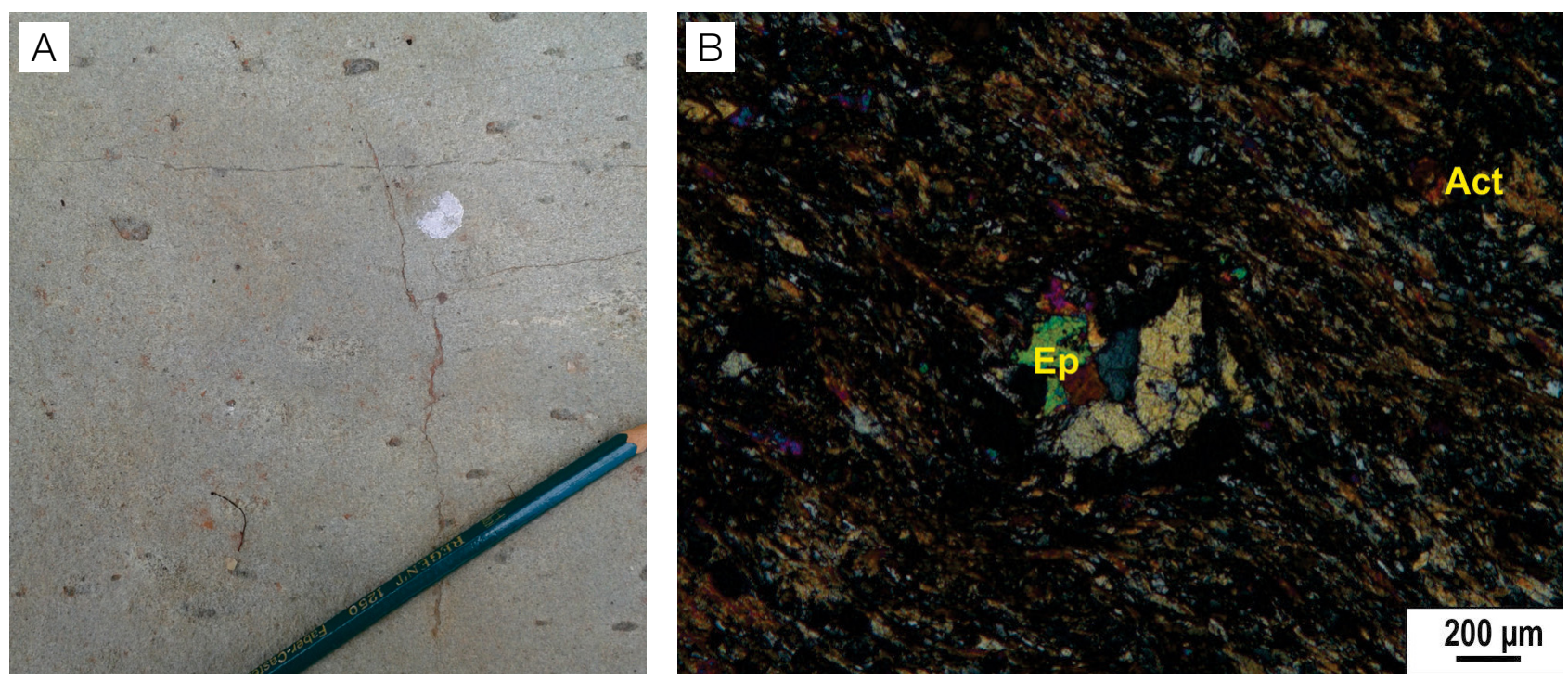

Act: actinolita; Ep: epidoto

Figura 6. Xistos verdes com amígdalas primárias preservadas. (A) amígdalas macroscópicas; (B) amígdalas microscópicas.

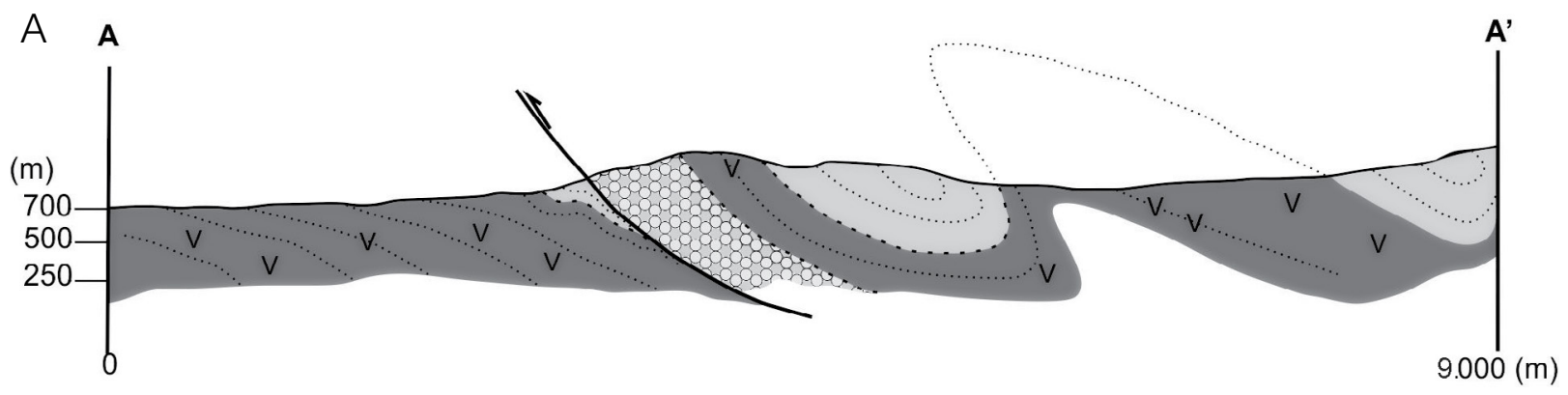

Sequência Metavulcano-sedimentar

Fo. São João da Chapada

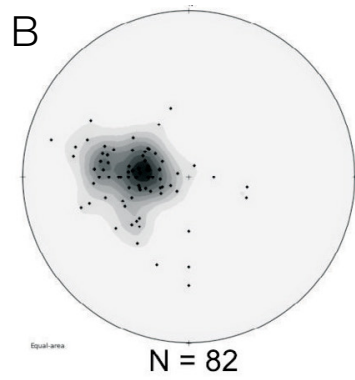

Máximo $=90 / 22$ (plano)

Guirlanda $=27 / 13$ (polo) $K=4,24 ; C=2,82$

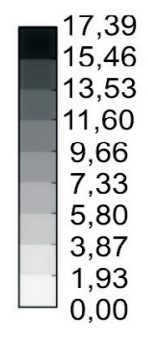

C

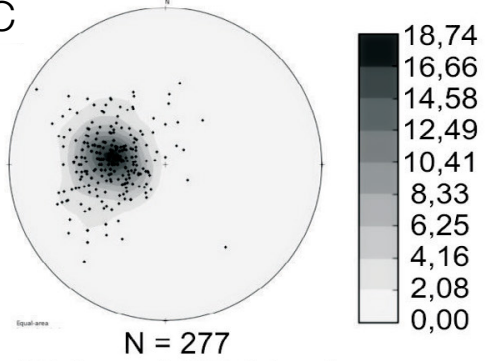

Máximo $=94 / 30$ (plano)

Guirlanda $=121 / 28$ (polo) $K=10,36 ; C=2,76$

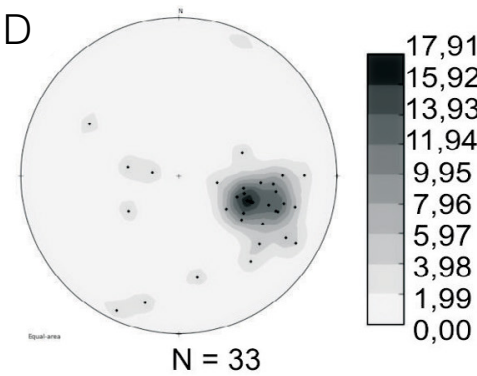

Máximo $=292 / 44$ (plano) Guirlanda $=06 / 16$ (polo) $K=3.91 ; C=2.06$

Figura 7. (A) Perfil geológico da região de Planalto de Minas; (B) estereograma do acamamento $S_{0}$; (C) estereograma da foliação $S_{1}$; (D) estereograma da segunda foliação $S_{2}$. 
específica da litosfera. Sob a luz da tectônica de placas, a formação, o desenvolvimento e a finalização de uma bacia rifte - abortada ou rompida - obedecem aos preceitos postulados pela tectônica global, definindo um ciclo geodinâmico específico, com as ressalvas impostas pelas condições locais, inerentes a cada bacia gerada (Kearey et al., 2014).

No Brasil, Pedrosa-Soares e Alkmim (2011) sugeriram seis eventos de rifteamento e/ou magmatismo anorogênico que afetaram as regiões ocupadas pelo cráton São Francisco e pelo Orógeno Araçuaí: E1 (Estateriano, 1,77 - 1,7 Ga), E2 (Calimiano, 1,57 - 1,5 Ga), E3 (Esteniano, 1,18 - ? Ga), E4 (no limite Esteaniano-Toniano, $c a .1 \mathrm{Ga}$ ), E5 (Toniano, 930 - $850 \mathrm{Ma}$ ) e E6 (Criogeniano, 750 - $670 \mathrm{Ma}$ ).

Os registros desses eventos por vezes são descontínuos e/ ou incompletos, distribuindo-se heterogeneamente por uma grande área. Esse fato é próprio da dinâmica formadora de bacias do tipo rifte, em que um meio-gráben, ou sistemas ramificados de meio-grabens, são elementos estruturais com forte influência do tipo e da trama do embasamento (Rosendahl et al., 1986; Kearey et al., 2014).

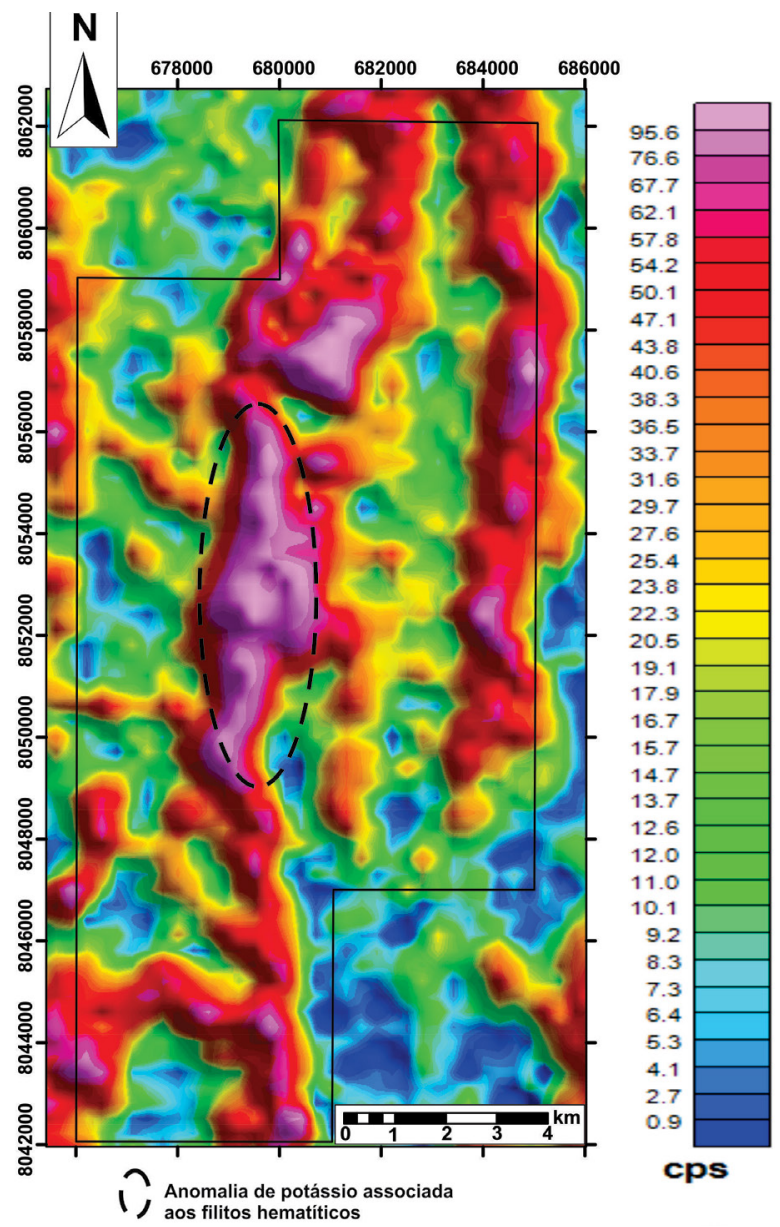

Figura 8. Mapa radiométrico do canal de potássio. A anomalia delimitada é associada à ocorrência do filito hematítico, cuja composição química é muito rica em potássio.
Em sua porção mineira, a serra do Espinhaço ocorre segmentada por uma descontinuidade física na altura do paralelo $17^{\circ} 30^{\prime} \mathrm{S}$, área abrangida por este trabalho, recebendo a designação de Serra do Espinhaço Meridional para a região compreendida a sul desse paralelo, e Serra do Espinhaço Setentrional mineira para o segmento norte, sendo que tais segmentos são separados por aproximadamente $30 \mathrm{~km}$, e o setor setentrional é deslocado em direção NNE da porção meridional (Figura 1). Essa descontinuidade geográfica possivelmente reflete a sobreposição de estruturas tectônicas formadoras de bacias sucessoras, com individualização de blocos e formação de meio-gráben ou sistemas ramificados de meio-grabens em períodos distintos.

O Supergrupo Espinhaço é entendido como um sistema de riftes intracontinentais de idade estateriana $(c a .1,7 \mathrm{Ga})$, calimiana ( $c a .1,6-1,3 \mathrm{Ga}$ ) e esteniana ( $c a .1,2 \mathrm{Ga}$ ), sucedido por

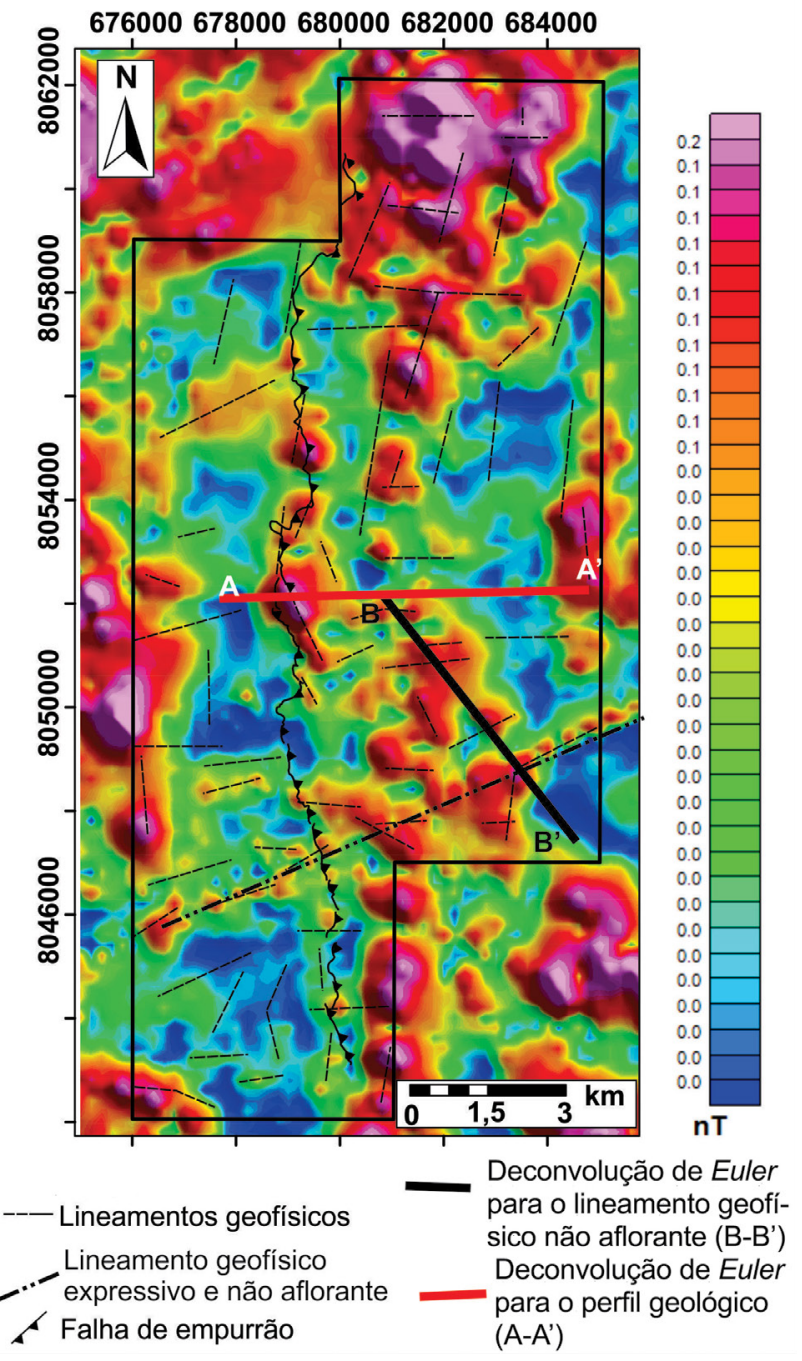

Figura 9. Mapa magnetométrico de amplitude do sinal analítico com os principais lineamentos geofísicos da região de Planalto de Minas. 


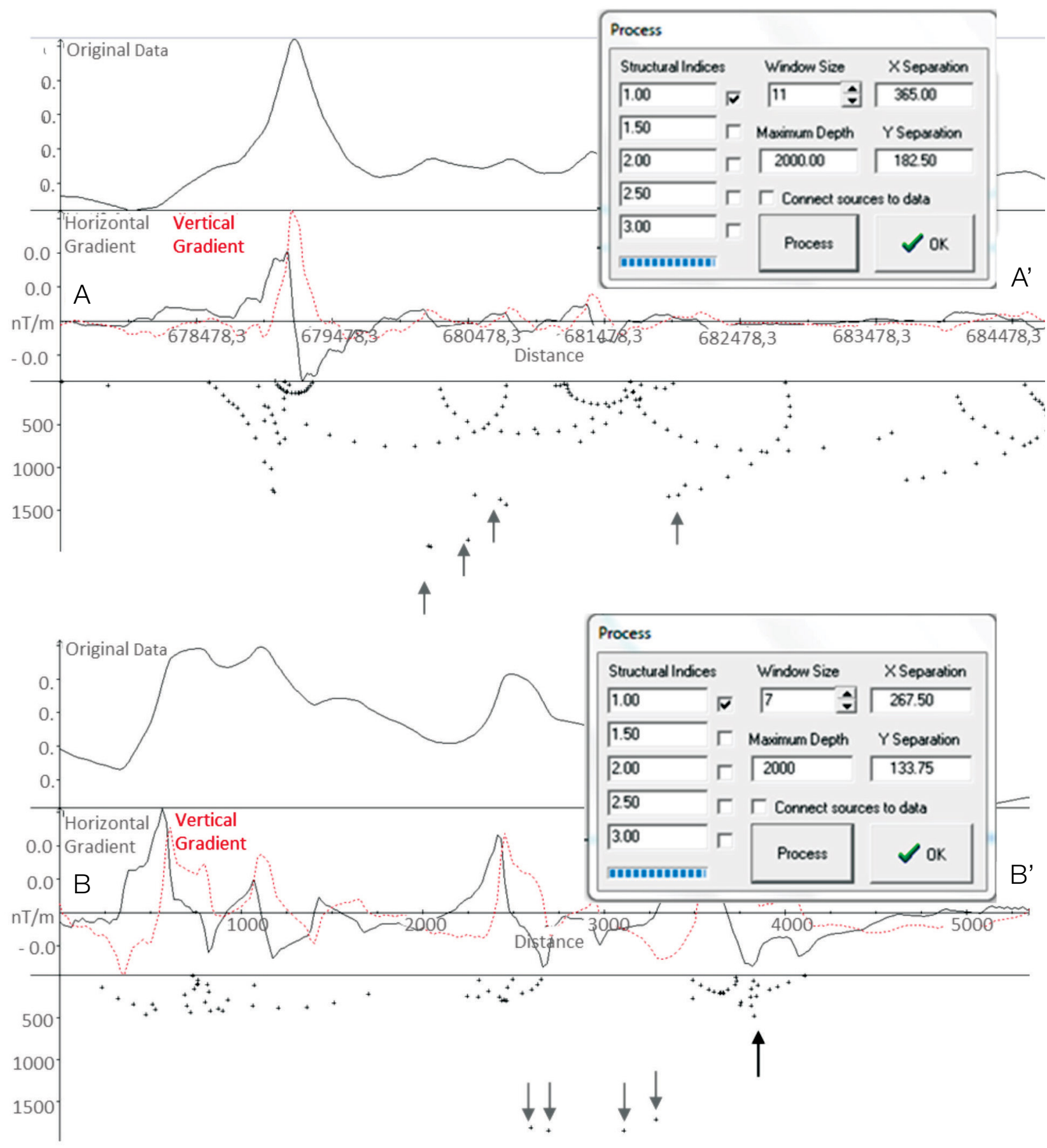

Figura 10. Deconvoluções de Euler (A-A' coincidente com o perfil geológico, B-B' perpendicular ao expressivo lineamento geofísico não aflorante), utilizadas para estumar a profundidade média das anomalias geofísicas e o possível arcabouço estrutural. As setas cinzas indicam a presença do embasamento cristalino, e a preta que a estrutura não aflorante possivelmente equivale a possíveis corpos máficos. 
uma bacia intracratônica do tipo sag (Chemale et al., 2012). A ausência de um ciclo bacinal intermediário $(1,6 \mathrm{Ga}-1,3 \mathrm{Ga})$, presente apenas na Chapada Diamantina, permite inferir que a atual região ocupada pela serra do Espinhaço Meridional comportou-se como um alto estrutural ou uma área de não deposição entre o Estateriano e o início do Esteniano. Situação semelhante deve ter ocorrido com o meio-gráben mais setentrional do rifteamento estateriano em Minas Gerais, representado pela Formação São João da Chapada na região de Planalto de Minas. Inexistem indícios dos rifteamentos calimiano e esteniano nessa região, assim como da fase sag do Supergrupo Espinhaço, sugerindo que parte significativa da área de Planalto de Minas pode ter sido uma área de não deposição ou ter servido como área-fonte para o preenchimento das bacias que se formaram a sul e a norte, do Calimiano ao limite Esteniano-Toniano (Figura 12).

O estágio rifte da bacia Macaúbas é bem documentado ao longo do meridiano $43^{\circ} 30^{`} \mathrm{~W}$, próxima à área de interesse

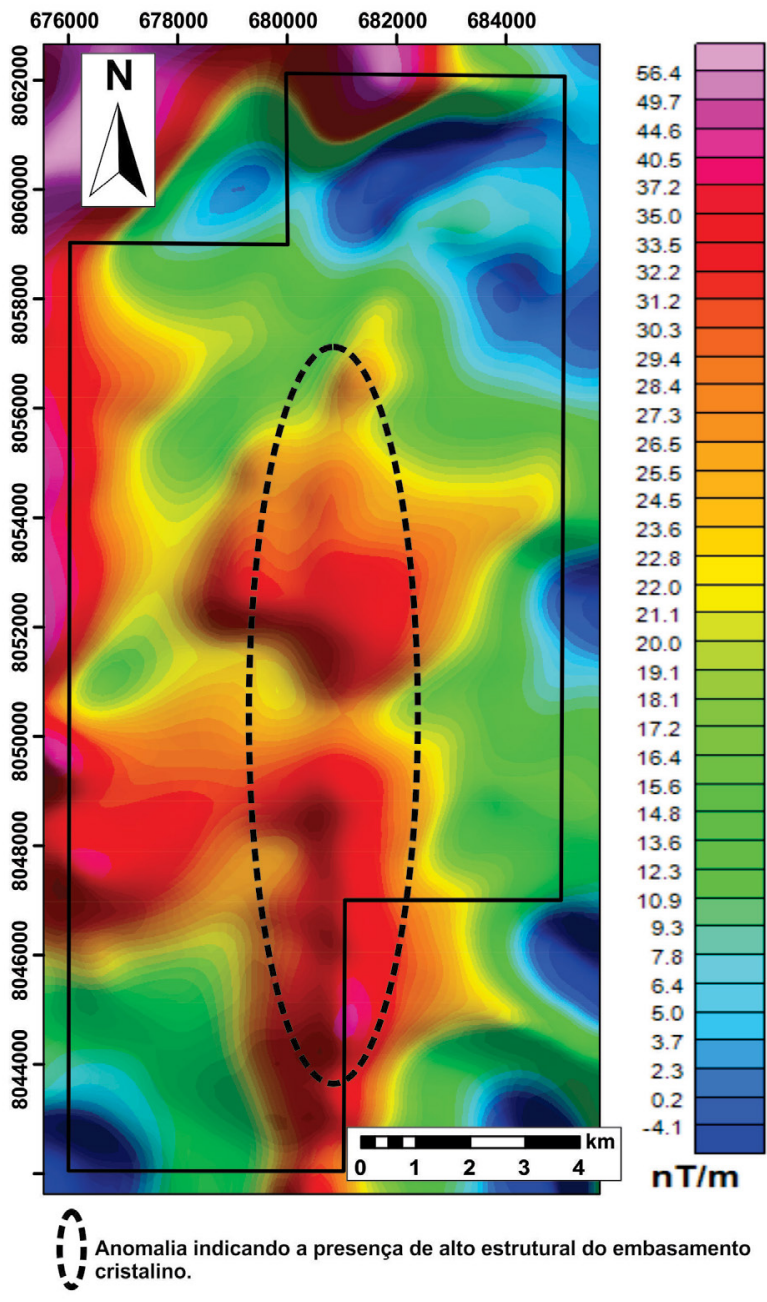

Figura 11. Mapa magnetométrico de continuidade para cima (Up500) com anomalias relacionadas à presença de rochas cristalinas, corroborando a existência de um alto estrutural do embasamento cristalino. deste trabalho, nas terminações periclinais dos anticlinais da serra do Espinhaço Meridional e Setentrional (ou de Itacambira, Figura 1). Martins et al. (2008) reconheceram a Formação Matão como a unidade do rifte Macaúbas na região de Itacambira, porção oeste da serra do Espinhaço Setentrional, assentada diretamente sobre os metassedimentos do Supergrupo Espinhaço. O padrão de sedimentação foi altamente condicionado pela tectônica extensional operante, fazendo com que a deposição dessa unidade tenha se associado ao desenvolvimento de um meio-gráben individual e de morfologia simples, possuindo um depocentro relativamente bem definido, com uma única falha mestra ou um sistema de falhas distributárias internas.

A Formação Capelinha, que consiste em uma espessa sequência metavulcano-sedimentar, registra a ramificação do rifte Macaúbas para leste em momento posterior a ca. $957 \mathrm{Ma}$, conforme Castro et al. (2013) e Castro (2014). Essa ramificação caracterizou a formação de um alto estrutural e de uma margem flexural com o soerguimento do bloco Guanhães.

A progressão do rifteamento promoveu o estiramento da crosta e a ascensão da astenosfera, marcando o eixo termal do rifteamento Toniano nessa região (Machado et al., 1989; Gradim et al., 2005; Babinski et al., 2005; Martins et al., 2011), notadamente entre os distritos de Terra Branca - Planalto de Minas e o Alto Rio Araçuaí (nas proximidades da cidade São Gonçalo do Rio Preto), onde se distribuem amplamente diques gabroicos (ca. 939 Ma; Souza, 2016) e xistos verdes metabasálticos (ca. 889 Ma; Souza, 2016).

O modo de associação das litofácies dos xistos verdes presentes na Formação Planalto de Minas permite interpretar que tais rochas formaram-se a partir de edifícios vulcânicos subaquosos de alta produtividade (fire fountaining), tal qual o modelo de Simpson e McPhie (1999), cronocorrelatos aos corpos de mesma natureza caracterizados por Gradim et al. (2005). Além disso, a intercalação dos corpos com o magnetita-sericita quartzito remetem a um ambiente marinho raso a intermediário.

Assim como implicitamente sugerido por Martins et al. (2008), o padrão de ocorrência das sequências do rifte Macaúbas na região de Itacambira-Terra Branca possivelmente se deve a inversões de caimento das margens flexurais ao longo da direção meridiana, com falhas de bordas convergentes e estruturações internas do meio-gráben em padrões complexos (Rosendahl et al., 1986). Esse fato permite inferir o mecanismo de formação do aqui denominado alto estrutural interno de Planalto de Minas.

\section{CONCLUSÕES}

O rifteamento Toniano, cujo registro parcial está representado na região de Planalto de Minas por uma sequência metavulcano-sedimentar de mesmo nome, sobrepõe-se diretamente ao rifteamento Estateriano (Formação São João da Chapada), 

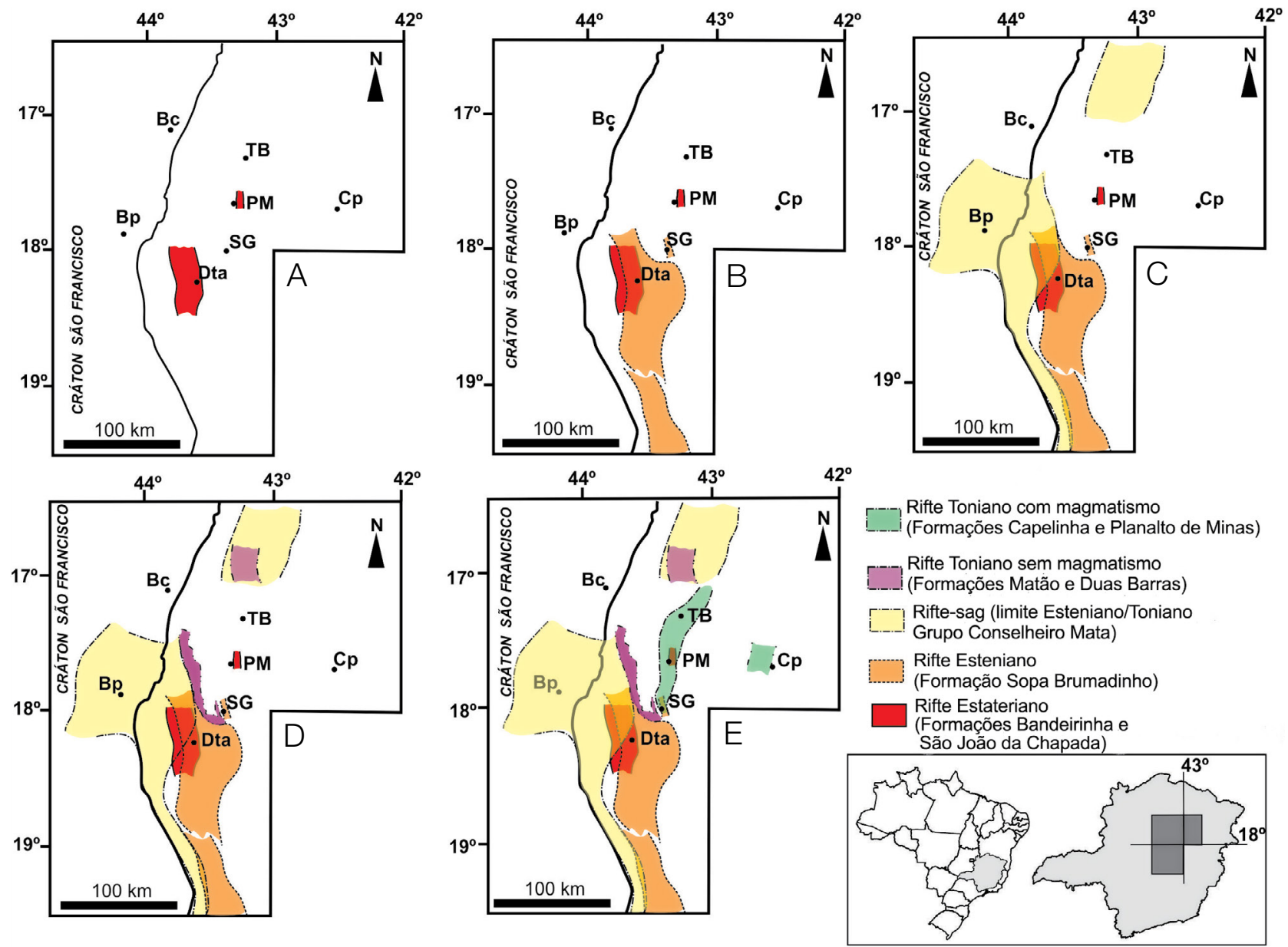

Bc: Bocaiúva; Bp: Buenópolis; Cp: Capelinha; Dta: Diamantina; PM: Planalto de Minas; TB: Terra Branca; SG: São Gonçalo do Rio Preto.

Figura 12. Ciclos de rifteamento que atingiram o paleocontinente São Francisco-Congo. (A) Ciclo Estateriano, com a deposição dos metassedimentos das formações Bandeirinha e São João da Chapada (Chemale et al., 2012); (B) Ciclo Esteniano, com a deposição dos metassedimentos da Formação Sopa Brumadinho (Chemale et al., 2012); (C) Ciclo do limite Esteniano/Toniano, com o registro da fase sag da bacia Espinhaço nos metassedimentos do Grupo Conselheiro Mata; (D) Ciclo Toniano, sem evidências de magmatismo associado, com a deposição dos metassedimentos da Formação Matão (Martins et al., 2008); (E) Ciclo Toniano, com magmatismo ultramáfico da Formação Capelinha (Castro, 2014) e magmatismo máfico da sequência metavulcano-sedimentar de Planalto de Minas (Souza, 2016).

revelando que a região de Planalto de Minas permaneceu como um alto estrutural ao final do Estateriano até o Toniano.

A existência do alto estrutural de Planalto de Minas revela parte do arranjo tectônico das bacias sucessoras do Orógeno Araçuaí em Minas Gerais, remetendo a um complexo arranjo estrutural dos rifteamentos sobrepostos, com a formação e a interação entre um meio-gráben, ou um sistema ramificado de meio-grabens, que exerceram importante controle tectono-estratigráfico na arquitetura da bacia Macaúbas (lato sensu).

\section{AGRADECIMENTOS}

A autora Maria Eugênia Silva de Souza agradece ao Conselho Nacional de Desenvolvimento Científico e Tecnológico (CNPq) pela concessão de sua bolsa de mestrado. Maximiliano de Souza Martins agradece em especial à Fundação de Amparo à Pesquisa do Estado de Minas Gerais (FAPEMIG) — processo CRAAPQ 04444/10 da Universidade Federal de Minas Gerais/Fundação de Desenvolvimento da Pesquisa - UFMG/ FUNDEP) - à Pró-reitoria de Pesquisa e Pós-graduação da Universidade Federal de Ouro Preto (PROPP-UFOP) —editais 02/2015 e 09/2016 - e ao CNPq (processo 305232/20134) pelo apoio e suporte financeiro para a realização desta pesquisa. Agradecemos ao engenheiro geólogo Mateus Lima Rosa pela inestimável contribuição na confecção dos mapas geofísicos, ao Departamento de Geologia da Escola de Minas da Universidade Federal de Ouro Preto (DEGEO/EM/ UFOP) por viabilizar as etapas de campo e à Companhia de Desenvolvimento Econômico de Minas Gerais (CODEMIG) 
e ao Serviço Geológico Brasileiro (CPRM) por cederem os dados para a confecção dos mapas geofísicos.

\section{REFERÊNCIAS}

Alkmim, F. F. (2004). O que faz de um cráton um cráton? O Cráton do São Francisco e as revelações Almeidianas ao delimita-lo. In: V. Mantesso-Neto, A. Bartorelli, C. D. R. Carneiro, B. B. Brito-Neves (Eds), Geologia do Continente Sulamericano. Evolução da obra de Fernando Flávio Marques de Almeida (v. 2, 17-35). São Paulo: Becca.

Alkmim, F. F., Marshak, S., Pedrosa-Soares, A. C., Peres, G. G., Cruz, S., Whittington, A. (2006). Kinematic evolution of the Araçuaí-West Congo orogen in Brazil and Africa: nutcracker tectonics during the neoproterozoic assembly of Gondwana. Precambrian Research, 149, 43-64.

Alkmim, F. F., Martins-Neto, M. A. (2001). A Bacia Intracratônica do São Francisco: Arcabouço estrutural e cenários evolutivos. In: M. A. Martins-Neto, C. P. Pinto (Eds.). Bacia do São Francisco. Geologia e Recursos Minerais (9-30). Belo Horizonte: SBG.

Almeida, F. F. M. (1977). O Cráton do São Francisco. Revista Brasileira de Geociências, 7, 285-295.

Almeida-Abreu P. A. (1995). O Supergrupo Espinhaço: O rifte, a bacia e o orógeno. Geonomos, 3, 1-18.

Babinski, M., Gradim, R. J., Pedrosa-Soares, A. C., Alkmim, F. F., Noce, C. M., Liu, D. (2005). Geocronologia U-Pb (SHRIMP) e Sm-Nd de xistos verdes basálticos do Orógeno Araçuaí: implicações para a idade do Grupo Macaúbas. Revista Brasileira de Geociências, 35 (supl. 4), 77-81.

Babinski, M., Trindade, R., Pedrosa-Soares, A. C., Martins, M. S., Noce, C. M., Liu, D. (2012). Neoproterozoic glacial deposits from the Araçuaí orogen, Brazil: Age, provenance and correlations with the São Francisco craton and West Congo belt. Gondwana Research, 21, 451-465.

Cabral, A. R., Wiedenbeck, M., Koglin, N., Lehmann, B., Abreu, F. R. (2012). Boron-isotopic constraints on the petrogenesis of hematitic phyllite in the Southern Serra do Espinhaço, Minas Gerais, Brazil. Lithos, 140 (140-141), 224-233.

Castro, M. P. (2014). Caracterização geológica da Formação Capelinha como uma unidade basal do Grupo Macaúbas em sua área tipo, Minas Gerais. Dissertação (Mestrado). Ouro Preto: Departamento de Geologia - UFOP.
Castro, M. P., Queiroga, G. N., Martins, M., Dussin, I., PedrosaSoares, A. C., Alkmim, F. F., Silva, H. M. C., Endo, I. (2013). Caracterização lito-estrutural e geocronológica da Formação Capelinha na região homônima, Minas Gerais. XIII Simpósio de Geologia do Sudeste - GEOSUDESTE. Juiz de Fora: SBG.

Chemale, F., Dussin, I. A., Alkmim, F. F., Martins, M. S., Queiroga, G. N., Arsmtrong, R., Santos, M. N. (2012). Unravelling a Proterozoic basin history through detrital zircon geochronology: The case of the Espinhaço Supergroup, Minas Gerais, Brazil. Gondwana Research, 22(1), 200-206.

Chula, A. M. D., Knauer, L. G., Almeida-Abreu, P. A. (1995). Estratigrafia do Supergrupo Espinhaço na região de Planalto de Minas, Diamantina - MG. Geonomos, 3(2), 69-81.

Dussin, I. A., Dussin, T. M. (1995). Supergrupo Espinhaço: modelo de evolução geodinâmica. Geonomos, 3, 19-26.

Fogaça, A. C. C. (1996). Mapa Geológico da Folha Diamantina, Minas Gerais, Brasil. Projeto Espinhaço. Belo Horizonte: COMIG/UFMG.

Gradim, R. J., Alkmim, F. F., Pedrosa-Soares, A. C., Babinski, M., Noce, C. M. (2005). Xistos verdes do Alto Araçuaí, Minas Gerais: Vulcanismo básico do rifte Neoproterozóico Macaúbas. Revista Brasileira de Geociências, 35, 59-69.

Grossi-Sad, J. H., Lobato, L. M., Pedrosa-Soares, A. C., Soares Filho B. S. (1997). Projeto Espinhaço em CD-ROM (textos, mapas e anexos). Belo Horizonte: COMIG. 2693p.

Hettich, M. (1973). Zur stratigraphie und gênese dês Macaúbas nordlich der Serra Negra, Espinhaço-Zone, Minas Gerais, Brasilien. Tese (Doutorado). Freiburg: Universität Freiburg.

Karfunkel, B., Karfunkel, J. (1977). Fazielle entwicklung der mittleren Espinhaço-zone mit besonderer Brücksichtigung des tillit-problems. Geoogisches Jarbuch, 24, 3-91.

Kearey, P., Klepeis, K. A., Vine, F. J. (2014). Tectônica Global. 3. ed. Chichester: Wiley-Blackwell.

Knauer, L. G., Schrank, A. (1994). A origem dos filitos hematíticos da Serra do Espinhaço Meridional, Minas Gerais. Geonomos, 1(1), 33-38.

Kuchenbecker, M., Pedrosa-Soares, A. C., Babinski, M., Fanning, M. (2015). Detrital zircon age patterns and provenance assessment for pre-glacial to post-glacial successions of the Neoproterozoic Macaúbas Group, Araçuaí orogen, Brazil. Precambrian Research, 266, 12-26. 
Kuchle, J. (2010). Análise tectono-estratigráfica de bacias rifte. Tese (Doutorado). Porto Alegre: Instituto de Geociências - UFRGS.

Lasa Engenharia e Prospecções. (2007). Relatório Final do Levantamento e Processamento dos Dados Magnetométricos e Gamaespectrométricos. Área 11A - Jaiba - Montes ClarosBocaiúva. Levantamento Aerogeofísico de Minas Gerais de 2008 -2009. Belo Horizonte: Secretaria de Estado de Desenvolvimento Econômico de Minas Gerais (SEDE).

Machado, N., Schrank, A., Abreu, F. R., Knauer, L. G., AlmeidaAbreu, P.A. (1989). Resultados preliminares da geocronolgia U/ $\mathrm{Pb}$ na Serra do Espinhaço Meridional. V Simpósio de Geologia de Minas Gerais (v.1, 171-174). Belo Horizonte: SBG.

Madeira, M. R. (2014). Mapeamento Geológico em Escala 1:25.000 dos Xistos Verdes e Rochas Encaixantes Localizados Entre os Distritos de Planalto de Minas e Desembargador Otoni, $M G$. Monografia (Trabalho de Conclusão de Curso). Ouro Preto: Departamento de Geologia - UFOP.

Martins, M, Babinski, M., Noce, C. M., Queiroga, G. N., Pedrosa-Soares, A. C., Trindade, R., Liu, D. (2011). A Suíte Córrego Taquari no Anticlinal de Itacambira, bacia do rio Macaúbas (MG): magmatismo básico tardi-ediacarano (ca. $560 \mathrm{Ma}$ ) do domínio externo do Orógeno Araçuaí. Geonomos, 19(2), 78-89.

Martins, M., Karfunkel, J., Noce, C. M., Babinski, M., PedrosaSoares, A. C., Sial, A. N., Liu, D. (2008). A sequência pré-glacial do Grupo Macaúbas na área-tipo e o registro da abertura do Rifte Araçuaí. Revista Brasileira de Geociências, 38(4), 761-772.

Martins-Neto, M. A., Alkmim F. F. (2000). Estratigrafia e evolução tectônica das bacias neoproterozóicas do Paleocontinente São Francisco e suas margens: registro da quebra de Rodínia e colagem de Gondwana. In: C. P. Pinto, M. A. Martins Neto (Eds.). Bacia do São Francisco: geologia e recursos minerais (31-54). Belo Horizonte: SBG MG.

Noce, C. M. (1997). Texto explicativo da Folha Itacambira. In: J. H. Grossi-Sad, L. M. Lobato, A. C. Pedrosa-Soares, B. S. Soares Filho (Eds.), Projeto Espinhaço em CD-ROM. Belo Horizonte: COMIG-UFMG.

Pedrosa-Soares, A. C., Alkmim, F. F. (2011). How many rifting events preceded the development of the AraçuaíWest Congo orogen? Geonomos, 19(2), 244-251.

Pedrosa-Soares, A. C., Noce, C. M., Alkmim, F. F., Silva, L. C., Babinski, M., Cordani, U., Castañeda, C. (2007). Orógeno Araçuaí: síntese do conhecimento 30 anos após Almeida 1977. Geonomos, 15(1), 1-16.
Pedrosa-Soares, A. C., Noce, C. M., Wiedemann, C. M., Pinto, C. P. (2001). The Araçuaí-West Congo orogen in Brazil: An overview of a confined orogen formed during Gondwanland assembly. Precambrian Research, 110, 307-323.

Pflug, R. (1968). Observações sobre a Estratigrafia da Série Minas na Região de Diamantina. Rio de Janeiro: DNPM/DFPM. 20 p.

Queiroga, G. N., Pedrosa-Soares, A. C., Noce, C. M., Alkmim, F. F., Pimentel, M. M., Dantas, E., Martins, M., Castañeda, C., Suita, M. T. F., Prichard, H. (2007). Age of the Ribeirão da Folha ophiolite, Araçuaí Orogen: The U-Pb Zircon (la-icpms) dating of a plagiogranite. Geonomos, 15(1), 61-65.

Reid, A. B., Allsop, J. M., Granser, H., Millet, A. J., Somerton, I. W. (1990). Magnetic interpretation in three dimensions using Euler deconvolution. Geophysics, 55, 80-91.

Rosendahl, B. R., Reynolds, D. J., Lorber, P. M., Burgess, C. F., McGill, J., Scott, D., Lambiase, J. J., Derksen, S. J. (1986). Structural expressions of rifting: lessons from Lake Tanganyika, Africa. In: L. E. Frostick, R. W. Renaut, I. Reid, J. J. Tiercelin (Eds.). Sedimentation in the Africans rifts (29-43). Oxford: Geological Society (Geological Society Special Publication, 25).

Schobbenhaus, C. (1993). O Proterozóico Médio no Brasil com ênfase à região Centro-leste, uma revisão. Tese (Doutorado). Freiburg: Universität Freiburg.

Schöll, W., Fogaça, A. C. C. (1979). Estratigrafia da Serra do Espinhaço na região de Diamantina. I Simpósio de Geologia de Minas Gerais (55-73). Diamantina: SBG.

Schrank, A., Dourado, B. C. V., Biondi, J. C. (1978). Estudo preliminar dos meta-vulcanitos do Grupo Macaúbas na região do alto Jequitinhonha-MG. XXX Congresso Brasileiro de Geologia (v. 3, 1323-1335). Recife: SBG.

Simpson, K., McPhie, J. (1999). Fluidal-clast breccia generated by submarine fire fountaining, Trooper Creek Formation, Queensland, Australia. Journal of Volcanology and Geothermal Research, 109, 339-355.

Souza, M. E. S. (2016). Caracterização Litoestrutural e Geocronológica dos Metagabros e Xistos Verdes do Grupo Macaúbas na Faixa Terra Branca - Planalto de Minas, Minas Gerais. Dissertação (Mestrado). Ouro Preto: Departamento de Geologia - UFOP.

Uhlein, A. (1991). Transição cráton-faixa dobrada: um exemplo do Cráton do São Francisco e da Faixa Araçuaí (ciclo Brasiliano) no Estado de Minas Gerais. Tese (Doutorado). São Paulo: Instituto de Geociências - USP. 